\title{
Vaginal repaired cesarean section diverticulum is beneficial in women with two prior cesarean sections
}

\author{
Yizhi Wang, Jiarui Li, Husheng Wang ${ }^{*}$ and Xipeng Wang ${ }^{*}$
}

\begin{abstract}
Background: The aim of this study was to evaluate the effect of vaginal repair in patients with cesarean section diverticulum (CSD) who had one or two previous cesarean sections (CSs).

Methods: From January 2012 to December 2014, 248 women with CSD underwent vaginal repair surgery in Shanghai First Maternity and Infant Hospital. These included 193 women with one previous cesarean section and 55 women with two previous cesarean sections. Excision and suture of CSD was performed through a vaginal approach. The duration of menstruation, the length, width and depth of the CSD and thickness of the remaining muscular layer (TRM) were evaluated before and after surgery by transvaginal three-dimensional (3D) color Doppler ultrasound.

Results: A total of 221 (89.11\%) women were followed-up for more than 3 months, and 168 (67.74\%) women were followed-up for more than 6 months. There were significant differences in the average duration of menstruation ( $7.77 \pm 2.05$ and $8.02 \pm 2.06$ days VS $13.99 \pm 3.71$ days), the average size of CSD (5.54*9.19*5.60 and 5.75*9.04*6.18 $\mathrm{mm}$ VS $\left.7.99^{*} 12.43^{*} 6.62 \mathrm{~mm}\right)$ and the TRM $(7.61 \pm 2.52$ and $7.60 \pm 3.00 \mathrm{~mm}$ VS $2.51 \pm 1.02 \mathrm{~mm})$ after surgery compared with those figures before surgery. The results of this study reveal that vaginal repair could shorten the duration of menstruation and improve anatomical defects $(P<0.05)$. Moreover, there was no significant difference in the effect of clinical repair between women with one or two previous cesarean sections $(P>0.05)$.
\end{abstract}

Conclusion: In CSD patients, the clinical effectiveness of vaginal repair was equivalent between women with one or two previous cesarean sections.

Keywords: Cesarean section diverticulum, Thickness of remaining muscular layer, Duration of menstruation, Vaginal repair

\section{Background}

The rate of cesarean section (CS) has increased over the last few decades $[1,2]$. In 2008, $64.1 \%$ of urban women received cesarean section deliveries [3]. Compared with vaginal delivery, cesarean section is associated with a three- to six-fold higher risk of severe complications,

\footnotetext{
* Correspondence: wanghusheng@xinhuamed.com.cn; wangxipeng@xinhuamed.com.cn

Departments of Gynecology and Obstetrics, Xin Hua Hospital Affiliated with Shanghai JiaoTong University School of Medicine, 1665 Kong Jiang Road, Shanghai 200092, China
}

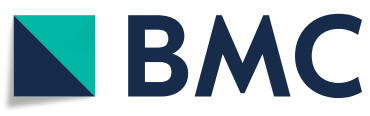

( ) The Author(s). 2020 Open Access This article is licensed under a Creative Commons Attribution 4.0 International License, which permits use, sharing, adaptation, distribution and reproduction in any medium or format, as long as you give appropriate credit to the original author(s) and the source, provide a link to the Creative Commons licence, and indicate if changes were made. The images or other third party material in this article are included in the article's Creative Commons licence, unless indicated otherwise in a credit line to the material. If material is not included in the article's Creative Commons licence and your intended use is not permitted by statutory regulation or exceeds the permitted use, you will need to obtain permission directly from the copyright holder. To view a copy of this licence, visit http://creativecommons.org/licenses/by/4.0/. The Creative Commons Public Domain Dedication waiver (http://creativecommons.org/publicdomain/zero/1.0/) applies to the data made available in this article, unless otherwise stated in a credit line to the data. such as intermenstrual bleeding, chronic pelvic pain, and the risk of secondary infertility, such as scar pregnancy, uterine rupture, placenta previa and accreta, all of which are now more common. All of these complications are associated with a new term in gynecologic disease. In a recent study, $64.5 \%$ of women who underwent cesarean section had cesarean section diverticulum (CSD), which causes abnormal uterine bleeding and other symptoms, within 6-12 weeks after surgery [4]. More than other complications, cesarean section scar ectopic pregnancies 
and CSD increase the risk of hemorrhoea or uterine rupture, which can threaten both the mother and her fetus's lives $[5,6]$.

CSD is associated with two primary complications: abnormal uterine bleeding, which mainly presents as a longer duration menstruation period [7], and the thickness of the remaining muscular layer (TRM). Among these two complications, longer menstrual bleeding is a serious problem for many women. Additionally, using sanitary towels over a long period of time can lead to vaginitis and influence their social activities.

No guidelines are available for the treatment of CSD. In China, three main treatments have been proposed in recent years. One is to use traditional Chinese medicine to accommodate the menstrual period; however, this has a poor effect in shortening the menstrual period and has no effect on the muscular layer. The second method is to take oral contraceptives or receive placement of the Levonorgestrel intrauterine system (Mirena). However, not all women have a good response to these two therapies. Additionally, once the patient withdraws from the treatment, the symptoms of abnormal uterine bleeding return, and this therapy does not enhance the TRM. The third treatment is surgery. At present, there are three choices of operation methods: laparoscopic operation, hysteroscopy and vaginal repair $[8,9]$.

In a previous study, we showed that vaginal repair of CSD can improve the symptoms of postmenstrual spotting and anatomically correct its scars [10]. The purpose of this study was to compare the effects of vaginal repair between women with one or two previous cesarean sections.

\section{Methods}

\section{Patients}

We conducted a observational cohort study of data obtained in 248 patients with CSD who underwent vaginal repair between January 2012 and December 2014 in Shanghai First Maternity and Infant Hospital. In all, 193 of the women had one previous cesarean section and were included in Group A, while 55 of the women had two previous cesarean sections and were included as Group B. This study was approved by the Ethics Committee of Shanghai First Maternity and Infant Hospital affiliated with Tongji University (KS1512) and conducted in accordance with the Declaration of Helsinki. All patients signed written informed consent to participate in this study.

\section{Vaginal repair}

All patients underwent vaginal repair at 7 to 14 days after menstruation. All procedures were conducted under epidural anesthesia and general anesthesia, and patients were placed in the lithotomy position. All surgical procedures reported in the current series were performed by the same surgeon. The only difference that we found was that some severe tissue adhesion was observed during the surgical procedure in patients who had two previous cesarean sections.

\section{Evaluation and follow-up}

We recorded all patients' ages and their duration of menstruation before the surgery, and all of the patients were examined by transvaginal three-dimensional (3D) color Doppler ultrasound before the fourteenth day of menstruation to record their size of CSD as well as the TRM. TRM was measured from the interface between the uterine and the bladder wall to the bottom of the CSD. Length and depth were measured in sagittal plane and width were measured in transverse plane where the axis of the cervical canal can be demonstrated in relation to the lower segment and the uterine fundus.(Fig. 1) [11, 12]. After the surgery, the average temperature and the counts of leukocytes and hemoglobin in peripheral blood collected on the first day after surgery were evaluated. Additionally, the hospitalization duration and medical expenditures of the patients were also included in our study. At 3 and 6 months after surgery, the patients returned to the clinic provide data on the duration of their menstrual period. We then examined their TRM and the size of CSD by transvaginal ultrasound (TVU).

\section{Statistical analysis}

Student-Newman-Keuls test and Bonferroni method were used to assess intergroup differences in the size of CSD, TRM and the duration of the menstrual period before and after surgical treatment. All of these data are expressed as the mean \pm standard deviation (SD) or number (percentage). The outcomes of patients in different groups were compared using a completely random design ANOVA. $P<0.05$ was considered statistically significant. Statistical analysis was performed using SPSS software version 18.0 (IBM, Chicago, IL, USA) and Systat Sigma Plot version 12.5 (Systat Software Inc., San Jose, CA, USA).

\section{Results}

As shown in Table 1, a total of 248 patients were hospitalized and underwent vaginal repair. Of these, 193 had one and 55 had two previous cesarean sections. The average age was $32.64 \pm 3.84$ years old $(P>0.05)$. There was no significant difference in the duration of the menstrual period between before and after cesarean section $(P>0.05)$. Women with two prior cesarean sections suffered more severe symptoms with longer abnormal uterine bleeding. Before vaginal repair, the TRM of those who had two cesarean sections was higher than that found in women who had one prior cesarean section $(3.17 \pm 1.56 \mathrm{~mm}) \quad(P<0.05)$. There were no significant 

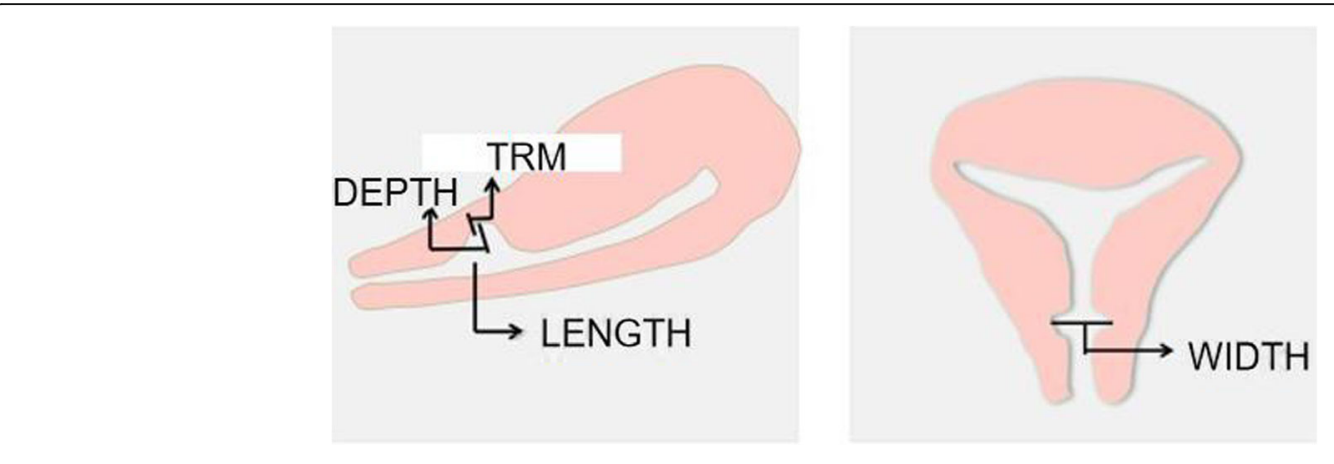

Fig. 1 Ultrasonographic assessment of the cesarean section scar

differences in hospitalization duration, medical expenditures incurred by inpatients, and leukocyte and hemoglobin counts after the surgery.

According to the ultrasound data, a total of 223 women $(89.92 \%)$ had visible CSD (Table 2). However, at 3 months after the surgery, only 63 and 18 of the patients who had one and two prior cesarean sections, respectively, still had CSD. At 6 months after vaginal repair, these numbers decreased to $45(23.32 \%)$ and 12 (21.82\%), respectively. Of those who still had CSD, the size of the CSD was significantly smaller than before the surgery $(P<0.05)$. However, there was no significant difference between the two groups $(P>0.05)$.

The duration of menstruation and the TRM after vaginal repair had both significantly improved after the surgery $(\mathrm{P}<0.05)$. At 3 months after the surgery, there was no obvious difference between the groups in the TRM (Table 3). At 6 months postoperative (Table 3), 130 of the women $(67.36 \%)$ who had one prior cesarean section and 38 of the women (69.10\%) who had two prior cesarean sections returned to the clinic for evaluation. They all showed significant improvement in the duration of menstruation as well as the TRM. The average duration of menstruation had decreased from $14.52 \pm 3.29$ to $8.00 \pm 2.19$ days $(P<0.05)$. Nevertheless, there was no clear difference in the number of bleeding days between the two groups of patients $(P>0.05)$.

\section{Discussion}

In this study, we retrospectively analyzed outcomes in 248 patients who underwent vaginal repair surgery between January 2012 and December 2014. In all, 193 of them had one prior cesarean section, while 55 had two.

Recent analyses have suggested that while the optimal global cesarean section rate is almost $20 \%$, attempts to reduce cesarean section rates in developed countries have not worked [13]. In China, the rate is approximately 35\% [14], and the incidence of acquired diverticulum ranges from 4 to $30 \%$ and is mainly caused by poor healing following a cesarean section scars $[7,15]$.

Our country has enforced a two-child policy in recent years. Thus, many women have a cesarean section before they desire to have a second child. In these CSD patients, infertility is more common because the accumulated blood degrades the quality of sperm and the cervical mucus [16]. However, because the remaining muscular layer is thinner as a result of CSD, the risk of uterine rupture is significantly higher. Finally, with the promotion of the two-child policy, women who previously underwent one cesarean section are now more likely to experience two cesarean sections. Some of these women may experience abnormal uterine bleeding, which mainly presents as a longer duration menstruation period, compared to what had occurred before the cesarean section. Therefore, due to its long-term

Table 1 Characteristics of Patients in the Cohorts

\begin{tabular}{llll}
\hline & Group A $(n=193)$ & Group B $(n=55)$ & $P$ value \\
\hline Age $(y)$ & $32.48 \pm 3.67$ & $32.80 \pm 4.00$ & 0.27 \\
Duration of menstruation before CS (days) & $6.13 \pm 1.10$ & $6.27 \pm 1.06$ & 0.56 \\
Duration of menstruation after CS (days) & $13.99 \pm 3.71$ & $15.05 \pm 2.86$ & 0.049 \\
TRM before CS (mm) & $2.51 \pm 1.02$ & $3.17 \pm 1.56$ & 0.005 \\
Hospital stay (days) & $6.53 \pm 1.14$ & $6.85 \pm 0.95$ & 0.14 \\
Medical expenditure of inpatients (CNY) & $11,243.50 \pm 2581.30$ & $11,142.84 \pm 2261.77$ & 0.59 \\
Leukocyte after VR (10^g/L) & $8.18 \pm 2.30$ & $8.02 \pm 2.20$ & 0.89 \\
Hemoglobin after VR (g/L) & $105.73 \pm 12.04$ & $103.68 \pm 9.78$ & 0.07 \\
\hline
\end{tabular}

CS cesarean section, TRM thickness of remaining muscular layer, VR vaginal repair, CNY Chinese Yuan 
Table 2 The size of CSD before and after VR

\begin{tabular}{lll}
\hline & Group A $(n=193)$ & Group B $(n=55)$ \\
\hline Size of CSD before VR $(n, \%)$ & $7.99^{*} 12.43^{*} 6.62(172,89.12 \%)$ & $7.76^{*} 11.71^{*} 6.20(51,92.73 \%)$ \\
Size of CSD at 3 months after VR $(n, \%)$ & $5.54^{*} 9.19^{*} 5.60(63,32.64 \%)$ & $6.22^{*} 10.17^{*} 5.89(18,32.73 \%)$ \\
Size of CSD at 6 months after VR $(n, \%)$ & $5.75^{*} 9.04^{*} 6.18(45,23.32 \%)$ & $5.42^{*} 11.58^{*} 5.08(12,21.82 \%)$ \\
\hline
\end{tabular}

CSD cesarean section diverticulum, $V R$ vaginal repair

complications, CSD has recently received attention from more doctors.

Oral contraception is considered a conservative management option to treat CSD patients who have had two cesarean sections. One study showed that oral contraceptives improved patient symptoms by decreasing the volume of menstruation [17]. However, considering the ages of the affected patients, the use of oral contraceptives is controversial because of its potential risk of vein thrombosis [18].

Operative methods include hysteroscopy, laparoscopy and vaginal repair. Studies have indicated that compared to other surgical methods, vaginal repair for CSD is a minimally invasive procedure that allows good exposure and accurate resection $[10,17,19,20]$. It also clearly shortened the duration of menstruation and significantly increased the distance between the CSD and the serosa [21]. Additionally, transvaginal repair may be a more cost-effective and convenient surgical approach for the management of patients with previous cesarean scar defects [19].

For patient with two prior cesarean sections, the main objectives are to shorten the duration of menstruation and improve quality of life. However, regarding the clinical effectiveness after vaginal surgery, whether women with two prior cesarean sections achieve better outcomes following this procedure has remained unclear.

$\mathrm{Xu} \mathrm{HY}$ et al. found that repeated cesarean section is a risk factor for poor efficacy of scar repair, whether performed by laparoscopic surgery or transvaginal surgery (OR 9.75, 95\%CI 2.30-41.36, 0.002) [22]. Nevertheless, in our study, we found that the duration of menstruation was significantly shorter after surgery in both groups $(P<0.05)$. However, there was no significant difference between the two groups $(P>0.05)$.
Another main symptom of CSD is a thinner remaining muscular layer. Compared to the data obtained before surgery, at the 3-month and 6-month follow-ups, there were significant differences in the size of the CSD as well as the TRM $(\mathrm{P}<0.05)$. After vaginal repair, the average TRM was higher in group B than in group A. Hence, women with two prior cesarean sections achieved better outcomes than were achieved by those with one prior cesarean section. Finally, no complications, such as incomplete healing of the scar and bladder injury, were reported in the two groups.

In addition, there was an unknown problem. Before vaginal repair, the TRM was clearly higher in women with two prior cesarean sections than in those with one. According to some researchers, the cesarean section technique (i.e., single- or double-layer closure, whether or not a bladder flap is created, and closing of the peritoneum) plays an important role in niche development [23], and it has been proposed that placing continuous, nonlocking absorbable sutures in two layers without undue tightness (constricting/devascularizing) of the sutures is likely to result in good healing of uterine scar [24]. More research is needed to elaborate this point.

There are some limitations to our study. First, the sample size was limited in this paper, especially with regard for women with two prior cesarean sections. Second, the patients were seen for follow-up visits only after 3 and 6 months, and we need more follow-up data, particularly after 6 months, to determine long-term clinical effectiveness.

\section{Conclusions}

In summary, our findings indicate that vaginal repair is an appropriate and effective method for the anatomical repair of CSD that shortens the duration of

Table 3 The follow-up statistics of 3 and 6 months after VR

\begin{tabular}{llll}
\hline & Group A $(n=130)$ & Group B $(n=38)$ & P value \\
\hline Average Duration of menstruation at 3 months after VR (day) & $7.77 \pm 2.05$ & $8.06 \pm 2.11$ & 0.87 \\
Average TRM at 3 months after VR (mm) & $7.61 \pm 2.52$ & $8.04 \pm 2.58$ & 0.81 \\
Average Duration of menstruation 6 months after VR (day) & $8.02 \pm 2.06$ & $7.89 \pm 2.32$ & 0.44 \\
Average TRM after VR at 6 months after VR (mm) & $7.60 \pm 3.00$ & $8.22 \pm 2.41$ & 0.01 \\
\hline
\end{tabular}

TRM thickness of remaining muscular layer, $V R$ vaginal repair 
menstruation. This technique is equally effective in women who have had one and two cesarean sections. Because cesarean delivery is associated with increased long-term morbidity, the decision to perform cesarean section should always be carefully considered.

However, further studies performed on a larger scale and with longer follow-up times will certainly be needed to confirm our findings.

\section{Abbreviations}

CS: Cesarean section; CSD: Cesarean section scar diverticulum; MRI: Magnetic resonance imaging; OC: Oral contraception; TRM: Thickness of the remaining muscular layer; VR: Vaginal repair

\section{Acknowledgements}

Not applicable.

\section{Conflict of interest}

The authors report no conflicts of interest.

\section{Authors' contributions}

WXP, WHS and LJR proposed the conception, designed the study and were responsible for surgery. WYZ were responsible for patient recruitment, data collection, manuscript preparation. WXP and WYZ was responsible for data analysis \& interpretation and statistical analysis. All authors read and approved the final manuscript.

\section{Funding}

No funding

\section{Availability of data and materials}

The datasets generated and analysed during the current study are not publicly available due to related study still being in progress but are available from Yizhi Wang on reasonable request.The authors agreed to provide copies of the appropriate documentation if requested.

\section{Ethics approval and consent to participate}

This study was approved by the Ethics Committee of Shanghai First Maternity and Infant Hospital, affiliated with Tongji University (KS1512), and was conducted in accordance with the Declaration of Helsinki. All patients signed written informed consent to participate in this study.

\section{Consent for publication}

Not applicable.

\section{Competing interests}

The authors declare that they have no competing interests in this section.

Received: 29 June 2019 Accepted: 6 April 2020

Published online: 23 April 2020

\section{References}

1. Betran AP, Merialdi M, Lauer JA, Bing-Shun W, Thomas J, Van Look P, et al. Rates of caesarean section: analysis of global, regional and national estimates. Paediatr Perinat Epidemiol. 2007:21(2):98-113.

2. Luo L, Niu G, Wang Q, Xie HZ, Yao SZ. Vaginal repair of cesarean section scar diverticula. J Minim Invasive Gynecol. 2012;19(4):454-8.

3. Feng $X L, X u L, G u o ~ Y$, Ronsmans $C$. Factors influencing rising caesarean section rates in China between 1988 and 2008. Bull World Health Organ. 2012;90:30-9A.

4. Van der Voet L, Bij de Vaate A, Veersema S, Brölmann H, Huirne J. Longterm complications of caesarean section. The niche in the scar: a prospective cohort study on niche prevalence and its relation to abnormal uterine bleeding. BJOG Int J Obstet Gynaecol. 2014;121(2):236-44.

5. Marotta M-L, Donnez J, Squifflet J, Jadoul P, Darii N, Donnez O. Laparoscopic repair of post-cesarean section uterine scar defects diagnosed in nonpregnant women. J Minim Invasive Gynecol. 2013;20(3):386-91.
6. Talamonte VH, Lippi UG, Lopes RGC, Stabile SAB. Hysteroscopic findings in patients with post-menstrual spotting with prior cesarean section. Einstein. 2012;10(1):53-6.

7. de Vaate $A B$, Van der Voet $L$, Naji O, Witmer M, Veersema S, Brölmann $H_{\text {, }}$ et al. Prevalence, potential risk factors for development and symptoms related to the presence of uterine niches following cesarean section: systematic review. Ultrasound Obstet Gynecol. 2014;43(4):372-82.

8. Abacjew-Chmylko A, Wydra DG, Olszewska H. Hysteroscopy in the treatment of uterine cesarean section scar diverticulum: a systematic review. Adv Med Sci. 2017;62(2):230-9.

9. Vervoort A, Van der Voet L, Hehenkamp W, Thurkow A, Van Kesteren P, Quartero H, et al. Hysteroscopic resection of a uterine caesarean scar defect (niche) in women with postmenstrual spotting: a randomised controlled trial. BJOG Int J Obstet Gynaecol. 2018;125(3):326-34.

10. Zhou J, Yao M, Wang $H$, Tan W, Chen $P$, Wang $X$. Vaginal repair of cesarean section scar diverticula that resulted in improved postoperative menstruation. J Minim Invasive Gynecol. 2016:23(6):969-78.

11. Pomorski M, Fuchs T, Rosner-Tenerowicz A, Zimmer M. Standardized ultrasonographic approach for the assessment of risk factors of incomplete healing of the cesarean section scar in the uterus. Eur J Obstet Gynecol Reprod Biol. 2016;205:141-5. https://doi.org/10.1016/j.ejogrb.2016.08.032 Epub 2016 Aug 24.

12. Naji O, Abdallah Y. Bij De Vaate AJ, smith a, et al. standardized approach for imaging and measuring cesarean section scars using ultrasonography. Ultrasound Obstet Gynecol. 2012;39(3):252-9. https://doi.org/10.1002/uog. 10077 Review.

13. Robson SJ, de Costa CM. Thirty years of the World Health Organization's target caesarean section rate: time to move on. Med J Aust. 2017;206(4):181.

14. Li HT, Luo S, Trasande L, Hellerstein S, Kang C, Li J-X, et al. Geographic variations and temporal trends in cesarean delivery rates in China, 20082014. Jama. 2017;317(1):69-76.

15. Chauhan SP, Magann EF, Wiggs CD, Barrilleaux PS, Martin JN Jr. Pregnancy after classic cesarean delivery. Obstet Gynecol. 2002;100(5):946-50.

16. Nezhat C, Falik R, Li A. Surgical management of niche, isthmocele, uteroperitoneal fistula, or cesarean scar defect: a critical rebirth in the medical literature. Fertil Steril. 2017;107(1):69-71.

17. Zhang X, Yang M, Wang Q, Chen J, Ding J, Hua K. Prospective evaluation of five methods used to treat cesarean scar defects. Int J Gynecol Obstet. 2016; 134(3):336-9.

18. Medicine PCotASfR. Combined hormonal contraception and the risk of venous thromboembolism: a guideline. Fertil Steril. 2017;107(1):43-51.

19. Zhang Y. A comparative study of transvaginal repair and laparoscopic repair in the management of patients with previous cesarean scar defect. J Minim Invasive Gynecol. 2016;23(4):535-41.

20. Grace L, Nezhat A. Should cesarean scar defect be treated laparoscopically? A case report and review of the literature. J Minim Invasive Gynecol. 2016; 23(5):843.

21. Yao M, Chen H, Tao J, Li Y, Sun M, Zhu J, et al. Clinical research of transvaginal repair of cesarean scar diverticulum. Chin J Obstet Gynecol. 2015;50(7):500-4.

22. Xu HY, Yang MY, Zhang X, Wang Q, Yi XF, Ding JX, et al. Efficacy of caesarean scar defect repair in improving postmenstrual bleeding and factors associated with poor effect. J Obstet Gynaecol. 2017;37(8):1076-81.

23. Vervoort A, Uittenbogaard L, Hehenkamp W, Brölmann H, Mol B, Huirne J. Why do niches develop in caesarean uterine scars? Hypotheses on the aetiology of niche development. Hum Reprod. 2015;30(12):2695-702.

24. Sholapurkar SL. Etiology of cesarean uterine scar defect (niche): detailed critical analysis of hypotheses and prevention strategies and peritoneal closure debate. J Clin Med Res. 2018;10(3):166.

\section{Publisher's Note}

Springer Nature remains neutral with regard to jurisdictional claims in published maps and institutional affiliations. 